\section{Kirurgiske inngrep hos pasienter med alvorlig blødersykdom 1997-2014}

ORIGINALARTIKKEL

\section{MAY-LINN FAUSKE ANDERSEN}

Avdeling for blodsykdommer

Oslo universitetssykehus

Hun hadde ideen til studien og var ansvarlig for utformingen av den. Hun var ansvarlig for innsamling av dataene og utformet det første artikkelutkastet. Hun analyserte og tolket data og var ansvarlig for den endelige utformingen av artikkelen.

May-Linn Fauske Andersen er cand.med. og LIS1-lege.

Forfatteren har fylt ut ICMJE-skjemaet og oppgir ingen interessekonflikter.

\section{PÅL ANDRE HOLME}

Avdeling for blodsykdommer

Oslo universitetssykehus

og

Institutt for klinisk medisin

Universitetet i Oslo

Han analyserte og tolket data og var ansvarlig for den endelige utformingen av artikkelen. Han var ansvarlig for behandlingen av pasientgruppen $\mathrm{i}$ hele studieperioden.

Pål Andre Holme er overlege ved Avdeling for blodsykdommer, Oslo universitetssykehus, hvor han er fagansvarlig for blødersykdommer. Han er professor II ved Institutt for klinisk medisin, Universitetet i Oslo.

Forfatteren har fylt ut ICMJE-skjemaet og oppgir følgende interessekonflikter: Han har mottatt foredragshonorar fra Bayer, BioMarin, Novo Nordisk, Pfizer og Shire.

\section{GEIR E. TJØNNFJORD}

E-post: gtjonnfj@ous-hf.no Avdeling for blodsykdommer Oslo universitetssykehus og

Institutt for klinisk medisin Universitetet i Oslo

Han hadde ideen til studien og var ansvarlig for utformingen av den. Han analyserte og tolket data og var ansvarlig for den endelige utformingen av artikkelen. Han var ansvarlig for behandlingen av pasientgruppen i hele studieperioden.

Geir E. Tjønnfjord er avdelingsleder ved Avdeling for blodsykdommer, Oslo universitetssykehus, og professor II ved Institutt for klinisk medisin, Universitetet i Oslo.

Forfatteren har fylt ut ICMJE-skjemeaet og oppgir følgende interessekonflikter: Han har mottatt midler til forskning på blødersykdom fra Bayer. 
Som følge av god medisinsk behandling er forventet levealder hos pasienter med alvorlig blødersykdom nå nærmest normal. Det medfører et økende behov for behandling av sykdom relatert til livsstil og $ø$ kt levealder. Vi beskriver kirurgi hos pasienter med alvorlig blødersykdom i perioden 1997-2014.

\section{MATERIALE OG METODE}

Data ble hentet fra registeret knyttet til Nasjonal behandlingstjeneste for kirurgi, intervensjon og avansert diagnostikk ved blødersykdom. Pasientene ble kategorisert etter type blødersykdom og type inngrep i ortopediske og ikke-ortopediske kirurgiske inngrep.

\section{RESULTATER}

825 kirurgiske inngrep ble utført hos 286 pasienter. Antall inngrep økte fra 21 i 1997 til 66 i 2014. Økningen var knyttet til ikke-ortopediske inngrep: Det ble utført 4 slike inngrep i 1997 og 45 i 2014. Antall ortopediske inngrep varierte en del fra år til år, men viste ingen tydelig trend.

\section{FORTOLKNING}

Med $ø$ kende levealder sees et $\emptyset$ kende behov for behandling av sykdommer som ikke er kausalt relatert til blødersykdom. Leger med liten erfaring med pasienter med alvorlig blødersykdom vil måtte forholde seg til sykdom relatert til livsstil og alderdom hos denne pasientgruppen.

Blødersykdommer omfatter en rekke arvelige sykdommer med blødningstendens som den fremste kliniske manifestasjonen. Pasienter med mindre alvorlig blødersykdom blør dersom de skader seg eller gjennomgår et kirurgisk inngrep, mens pasienter med alvorlig sykdom kan oppleve invalidiserende eller livstruende blødning uten å være utsatt for en såkalt hemostatisk utfordring. De vanligste alvorlige blødersykdommene er hemofili A, hemofili B og FVII-mangel, hvor pasientene mangler henholdsvis koagulasjonsfaktor VIII, IX og VII. Den hyppigste blødersykdommen i Norge er imidlertid von Willebrands sykdom, men det er kun et fåtall som har denne sykdommen i alvorlig grad.

Invalidiserende leddskader som følge av gjentatte blødninger er den vanligste komplikasjonen ved alvorlig blødersykdom, og mange pasienter trenger ortopedisk kirurgi i løpet av livet (1). Det gjelder spesielt de pasientene som ikke har fått tilbud om primærprofylaktisk behandling fra tidlig barnealder (1). Behandlingstilbudet til pasienter med alvorlig blødersykdom har blitt stadig bedre, med det resultat at leveutsiktene til disse pasientene ikke lenger skiller seg særlig fra utsiktene til personer uten blødersykdom (2). Det har medført et økende behov for behandling av sykdommer knyttet til livsstil og alderdom, dvs. sykdommer som ikke er en direkte konsekvens av blødersykdommen, og som vanligvis behandles av leger med liten erfaring med blødere. Fra en forventet levealder på rundt elleve år for hundre år siden er forventet levealder for et barn født med alvorlig blødersykdom i dag nærmest normal $(3,4)$. Det er et $ø$ kende behov for kunnskap om og oppmerksomhet rundt denne pasientgruppen fordi flere leger i ulike spesialiteter vil måtte forholde seg til den.

I denne artikkelen presenterer vi utviklingen av behovet for to hovedtyper kirurgi hos pasienter med alvorlig blødersykdom i Norge i perioden 1997-2014: ortopedisk kirurgi pga. blødningsartropati som er kausalt relatert til blødersykdommen, og kirurgi pga. tilstander som ikke er kausalt relatert til blødersykdommen.

\section{Materiale og metode}

Materialet omfatter totalt 310 pasienter med alvorlig blødersykdom som fikk utført 
kirurgiske inngrep eller andre invasive diagnostiske eller terapeutiske prosedyrer ved Oslo universitetssykehus i perioden 1.1.1997-31.12.2014. Alvorlig blødersykdom blir i denne sammenhengen definert som blødersykdom som krever substitusjonsbehandling med koagulasjonsfaktorkonsentrat for å kunne gjennomføre kirurgiske inngrep uten risiko for blødningskomplikasjoner. 24 pasienter ble ekskludert fra videre omtale: 13 fikk utført akutt kirurgi ved traumer, 11 hadde ervervet blødersykdom av en eller annen type. 286 pasienter gjennomgikk elektive inngrep, og disse pasientene omtales nærmere.

Inngrepene ble inndelt i to hovedkategorier: ortopediske inngrep og ikke-ortopediske inngrep. De ikke-ortopediske inngrepene ble videre delt inn i fem kategorier: hjerte-karinngrep, inngrep pga. kreftsykdom, inngrep i mage-tarm-kanalen, mindre kirurgiske inngrep og andre kirurgiske inngrep. Mindre kirurgiske inngrep omfatter småinngrep som tanntrekkinger, fjerning av mindre hudlesjoner, cystoskopi m.m. Andre kirurgiske inngrep omfatter nevrokirurgisk inngrep, inngrep i øre-nese-hals regionen, gynekologiske inngrep m.m.

Kirurgi hos pasienter med alvorlig blødersykdom er en del av Nasjonal behandlingstjeneste for kirurgi, intervensjon og avansert diagnostikk ved blødersykdom ved Oslo universitetssykehus. Data til studien er hentet fra kvalitetsregisteret knyttet til den nasjonale behandlingstjenesten. Kvalitetsregisteret er opprettet etter pålegg fra Helsedirektoratet og er grunnlaget for den årlige rapporteringen til Helsedirektoratet fra behandlingstjenesten. Studien er godkjent av Personvernombudet ved Oslo universitetssykehus.

\section{Resultater}

Av 286 pasienter hadde 55,6 \% hemofili A, 19,6 \% hemofili B, 19,2 \% von Willebrands sykdom, $4,5 \%$ FVII-mangel og $1 \%$ andre blødersykdommer (tabell 1 ).

\section{Tabell 1}

Pasienter med alvorlig blødersykdom som fikk utført kirurgisk inngrep ved Oslo universitetssykehus i perioden 1997-2014: Antall kirurgiske inngrep per sykdomskategori og alder (median og spredning) ved siste utførte inngrep.

\begin{tabular}{|lrrr|}
\hline Blødersykdom & $\begin{array}{c}\text { Antall pasienter } \\
(\mathbf{n = 2 8 6})\end{array}$ & $\begin{array}{c}\text { Antall kirurgiske } \\
\text { inngrep(n= 825) }\end{array}$ & $\begin{array}{c}\text { Medianalder } \\
\text { (spredning) }\end{array}$ \\
\hline Hemofili A & 159 & 511 & $43(14-83)$ \\
\hline Hemofili B & 56 & 151 & $43(15-91)$ \\
\hline von Willebrands sykdom & 55 & 113 & $53(17-90)$ \\
\hline FVII-mangel' $^{\prime}$ & 13 & 43 & $51(19-76)$ \\
\hline Annen blødersykdom & 3 & 7 & $48(40-61)$ \\
\hline
\end{tabular}

${ }^{1}$ FVII-mangel $=$ mangel på koagulasjonsfaktor VII

Totalt ble det utført 825 invasive diagnostiske og terapeutiske prosedyrer, hvorav 345 (41,8\%) var ortopediske og 480 ( $58,2 \%)$ ikke-ortopediske. Av de ortopediske var 258 (74,8\%) primære inngrep, mens 87 ( $25,2 \%$ ) var sekundære (operasjoner utført i ledd hvor det tidligere er utført et ortopedisk inngrep).

Inngrepene ble utført hos 286 pasienter. Mediant antall inngrep per pasient var 3 (spredning 1-15). Medianalder i gruppen som fikk utført ortopediske inngrep, var 40 år (spredning 14-82 år). I gruppen som fikk utført ikke-ortopediske inngrep, var medianalder 47 år (spredning 14-91 år). Figur 1 viser antall ortopediske og ikke-ortopediske inngrep som ble utført hos pasienter i ulike aldersgrupper. 
Ortopedisk kirurgi I Ikke-ortopedisk kirurgi

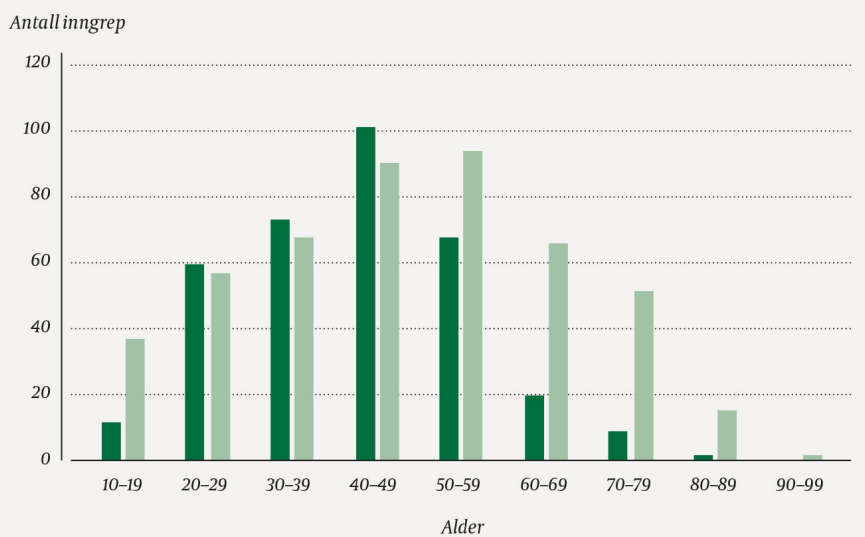

Figur 1 Antall ortopediske ( $n=345)$ og ikke-ortopediske $(n=480)$ inngrep etter alder i perioden 1997-2014 blant pasienter med alvorlig medfødt blødersykdom $(N=286)$.

I 314 (91\%) av de ortopediske inngrepene var det en klar sammenheng mellom selve inngrepet og pasientens blødersykdom, dvs. inngrepene ble utført pga. blødningsartropati og bestod i hovedsak av leddforbedrende inngrep (artroplastikk, reseksjoner, artrodeser, synovektomier). De resterende 31 inngrepene ble ikke utført på grunn av blødningsartropati, men av andre årsaker som for eksempel meniskruptur og korsbånd, sekvele etter tidligere fraktur, canalis carpi-syndrom m.m.

Figur 2 viser antall primære ortopediske inngrep og antall ikke-ortopediske inngrep utført per år hos pasienter med alvorlig blødersykdom i perioden 1997-2014. Inkludert alle typer ortopediske og ikke-ortopediske inngrep ble det utført 21 inngrep i 1997 og 66 i 2014. I begynnelsen av perioden var det først og fremst ortopediske inngrep som ble utført. Antall ortopediske inngrep per år varierte en god del, og viser ingen tydelig trend. Antall ikkeortopediske inngrep økte fra 4 i 1997 til 45 i 2014.

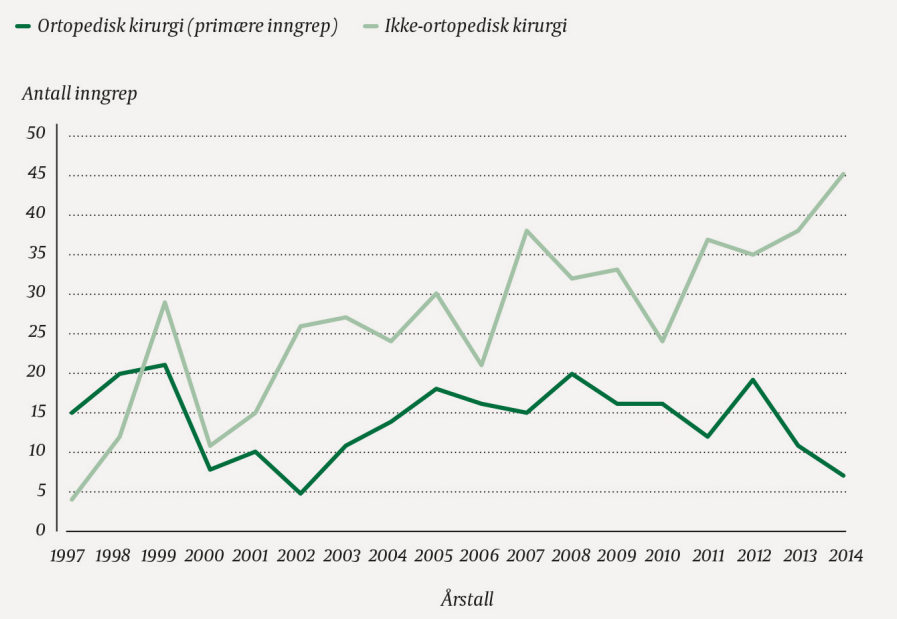

Figur 2 Antall primcere ortopediske inngrep og ikke-ortopediske inngrep utført på pasienter med alvorlig medfødt blødersykdom per år i perioden 1997-2014.

Av 48o ikke-ortopediske inngrep var 8,1\% hjerte-kar-kirurgi, 6,o \% kreftkirurgi, 21,3\% magetarm-kirurgi, 30,o \% mindre kirurgiske inngrep og 34,6\% andre kirurgiske inngrep.

\section{Diskusjon}

Studien viser et $ø$ kende antall kirurgiske inngrep hos pasienter med alvorlig medfødt blødersykdom i tidsrommet 1997-2014. Økningen er knyttet til ikke-ortopediske inngrep for sykdommer som ikke er kausalt relatert til blødersykdommen. Før 1995 var det nesten 
utelukkende ortopediske inngrep som ble utført hos pasienter med alvorlig blødersykdom $(6,7)$, og antall ortopediske inngrep har endret seg lite i studieperioden. Av de ortopediske inngrepene ble $91 \%$ utført pga. blødningsartropati.

I dag tilbyr vi barn med alvorlig blødersykdom primær profylaktisk behandling med koagulasjonsfaktorkonsentrat etter første leddblødning (ved 6-12 måneders alder). Dette har vist å redusere leddblødninger og utvikling av invalidiserende leddskader $(1,2)$. Primærprofylakse ble introdusert i Sverige flere år tidligere enn i Norge, og blødningsartropati var mindre prevalent blant svenske blødere sammenlignet med norske blødere i perioden 1989-99 (5). Vi forventer derfor en utvikling med avtakende behov for primære ortopediske inngrep pga. blødningsartropati. Vi har utført et stort antall ortopediske inngrep i tidligere år $(6,7)$, så vi forventer derimot at behovet for sekundære ortopediske inngrep vil være til stede i flere år framover.

I takt med at leveutsiktene for pasienter med alvorlig blødersykdom stadig blir bedre, har behovet for behandling av sykdommer som ikke er forårsaket av blødersykdommen, $\varnothing \mathrm{kt}$. Dette kommer tydelig frem av våre resultater og stemmer overens med funn $i$ andre observasjonsstudier $(8,9)$. Flere studier har vist at pasienter med alvorlig blødersykdom bl.a. har en $\emptyset$ kt risiko for å utvikle hypertensjon sammenlignet med personer uten blødersykdom (10-12).

Leger med liten erfaring med pasienter med blødersykdom vil med stor sannsynlighet komme i kontakt med disse pasientene, som nå i større grad rammes av aldersrelaterte sykdommer på samme måte som resten av befolkningen. Videre forskning som gir grunnlag for utvikling av egne retningslinjer for behandling av pasienter med alvorlig blødersykdom, vil være viktig i fremtiden $(13,14)$. Godt samarbeid mellom hematologer og leger i andre spesialiteter vil være viktig for å kunne gi bløderne best mulig behandling.

\section{HOVEDBUDSKAP}

I studieperioden $\emptyset \mathrm{kte}$ antall kirurgiske inngrep på pasienter med alvorlig blødersykdom fra 21 i 1997 til 66 i 2014

$\emptyset$ kningen var knyttet til inngrep for sykdommer som ikke var forårsaket av blødersykdommen, dvs. sykdommer knyttet til livsstil og $ø$ kt levealder

LITTERATUR:

1. Coppola A, Di Capua M, De Simone C. Primary prophylaxis in children with haemophilia. Blood Transfus 2008; 6 (suppl 2): s4-11. [PubMed]

2. Löfqvist T, Nilsson IM, Berntorp E et al. Haemophilia prophylaxis in young patients-a long-term follow-up. J Intern Med 1997; 241:395-400. [PubMed][CrossRef]

3. Lövdahl S, Henriksson KM, Baghaei F et al. Incidence, mortality rates and causes of deaths in haemophilia patients in Sweden. Haemophilia 2013; 19:362-9. [PubMed][CrossRef]

4. Larsson SA. Life expectancy of Swedish haemophiliacs, 1831-1980. Br J Haematol 1985; 59: 593-602. [PubMed][CrossRef]

5. Steen Carlsson K, Höjgård S, Glomstein A et al. On-demand vs. prophylactic treatment for severe haemophilia in Norway and Sweden: differences in treatment characteristics and outcome.

Haemophilia 2003; 9: 555-66. [PubMed][CrossRef]

6. Teigland JC, Tjønnfjord GE, Evensen SA et al. Synovectomy for haemophilic arthropathy: 6-21 years of follow-up in 16 patients. J Intern Med 1994; 235: 239-43. [PubMed][CrossRef]

7. Teigland JC, Tjønnfjord GE, Evensen SA et al. Knee arthroplasty in hemophilia. 5-12 year follow-up of 15 patients. Acta Orthop Scand 1993; 64: 153-6. [PubMed][CrossRef]

8. Canaro M, Goranova-Marinova V, Berntorp E. The ageing patient with haemophilia. Eur J Haematol 
2015; 94 (suppl 77): 17-22. [PubMed][CrossRef]

9. Konkle BA. The aging patient with hemophilia. Am J Hematol 2012; 87 (suppl 1): S27-32.

[PubMed][CrossRef]

10. Street A, Hill K, Sussex B et al. Haemophilia and ageing. Haemophilia 2006; 12 (suppl 3): 8-12.

[PubMed][CrossRef]

11. Lövdahl S. Co-morbidity and mortality in Swedish patients with haemophilia. Doktoravhandling. Malmö: Det medisinske fakultet, Universitetet i Lund, 2015.

12. Holme PA, Combescure C, Tait RC et al. Hypertension, haematuria and renal functioning in haemophilia - a cross-sectional study in Europe. Haemophilia 2016; 22: 248-55. [PubMed][CrossRef]

13. Fogarty PF, Mancuso ME, Kasthuri R et al. Presentation and management of acute coronary syndromes among adult persons with haemophilia: results of an international, retrospective, 10-year survey. Haemophilia 2015; 21: 589-97. [PubMed][CrossRef]

14. Schutgens RE, Klamroth R, Pabinger I et al. Management of atrial fibrillation in people with haemophilia-a consensus view by the ADVANCE Working Group. Haemophilia 2014; 20: e417-20. [PubMed][CrossRef]

Publisert: 6. mai 2019. Tidsskr Nor Legeforen. DOI: 10.4045/tidsskr.18.0592

Mottatt 26.6.2018, første revisjon innsendt 9.12.2018, godkjent 12.3.2019.

(C) Tidsskrift for Den norske legeforening 2020. Lastet ned fra tidsskriftet.no 